\title{
Le Premier baiser de l'amour
}

\author{
John E. Magerus
}

Un des événements les plus importants de La Nouvelle Hélö̈se se trouve dans la première partie et s'appelle la scène dans le bosquet. Julie, avec Claire comme témoin, consent à ce que Rousseau a intitulé "le premier baiser de l'amour." Cette scène est un des rares moments où les trois personnages principaux du roman sont ensemble. C'est à ce moment que Julie et Saint-Preux prennent conscience de la puissance de leur passion. Mais cette passion est impossible et dangereuse. Claire encourage Saint-Preux à partir pour la protection de sa cousine. Toute la suite du roman est le résultat de cet épisode: la structure "absence/ présence" y commence.

Rousseau a souligné 1'importance de cet événement en le choisissant comme le premier dans la série des douze estampes dont il voulait illustrer la première édition de son roman. L'histoire des difficultés que Rousseau a éprouvées avant de faire aboutir ce projet est racontée par Alexis François dans un livre intitulé Le Premier Baiser de l'Amour. Au dix-huitième siècle comme aujourd'hui, la question d'argent jouait un rôle très important dans la publication d'un livre. L'éditeur hollandais de Rousseau, Marc-Michel Rey, a refusé de financer le projet d'illustrations et Rousseau a dû faire préparer les estampes séparément et à ses frais.

Rousseau, qui aimait beaucoup les estampes, insistait sur la valeur des illustrations pour son 
livre. Dans ses efforts pour gagner l'appui de son éditeur, il a écrit: "les planches seules feraient le succès du livre. . . ." 2 On doute qu'il fût tout à fait sincère. Il voulait surtout que son lecteur participe au roman, et précisément les estampes donnent la possibilité d'élaborer ce qu'on vient de lire:

$$
\begin{aligned}
& \text { Si je n'aime pas beaucoup les } \\
& \text { tableaux, j'aime extrêmement les } \\
& \text { estampes, parce qu'elles laissent } \\
& \text { quelque chose à faire à mon imagi- } \\
& \text { nation. Elle les colore à sa fan- } \\
& \text { taisie, et il me semble alors que } \\
& \text { je vois les objets, tels qu'ils } \\
& \text { sont dans la nature. }
\end{aligned}
$$

L'art du graveur complète celui de l'écrivain. Comme sujet des douze estampes qu'il proposait, Rousseau a choisi les scènes les plus émouvantes du livre. Il a donné des indications assez précises au dessinateur et aux graveurs pour les aider dans la réalisation du projet. I1 ne voulait pas limiter la liberté de 1'artiste, mais il avait ses propres idées sur les scènes qu'il avait choisies, et croyait que c'était très important pour le lecteur de les voir de la même façon:

- . les détails dans lesquels je suis entré ne sont pas faits pour être executés à la lettre; ce n'est pas ce que le dessinateur doit rendre, mais ce qu'il doit savoir, afin d'y conformer son ouvrage autant qu'il est possible. Tout ce que j'ai décrit doit être dans sa tête, afin de mettre dans son estampe tout ce qui peut y entrer, et de n'y rien mettre de contraire. 4

Rousseau a scrupuleusement corrigé les dessins originaux et les épreuves. Il avait un oeil 
soucieux des détails les plus minuscules. Dans une lettre à son agent à Paris, François Coindet, il a écrit: 'Je me trompais. . . ce n'est pas l'oeil gauche de Julie qui est trop grand; c'est le droit qui est trop petit."5 Rien n'échappait à son attention: "Je trouve dans tous les dessins que Julie et Claire ont le sein trop plat. Les Suissesses ne 1 'ont pas ainsi. Probablement $M$. Coindet $\mathrm{n}$ 'ignore pas que les femmes de notre pays ont plus de tétons que les Parisiennes." 6 Il est poignant de remarquer que les estampes sont d'un format inférieur à une page des éditions Garnier. La publication du roman, sans les estampes, a eu lieu vers $1 \mathrm{a}$ fin de 1760 . Le recueil des estampes, dessinées par Gravelot et gravées par divers artistes, a paru au mois de février 1761. Dans ce recueil on a publié les notes détaillées de Rousseau intitulées "Sujets d'estampes," aussi bien que les indications sur la place des estampes dans le roman. On peut trouver des fac-similés des estampes originales avec les instructions complètes de Rousseau dans l'édition Classiques Garnier de La Nouvelle Héloĩse.

Le succès de La Nouvelle Héloïse et du recueil fut énorme. Immédiatement après la publication du roman on a commencé à ré-interpréter les sujets d'estampes. "Le Premier Baiser de l'Amour" a été une des scènes préférées au dix-huitième et dixneuvième siècles. Dans son livre du même titre, M. François a reproduit et a étudié un vingtaine de ces illustrations. Nous avons choisi cette scène aussi comme illustration de l'article précécent. Le paragraphe suivant a été traduit et proposé à la classe de dessin des messieurs Henderson et Jacobson de I'Université du Kansas. Nous ne savons pas si Rousseau serait d'accord avec notre choix, mais nous croyons que cette interprétation est dans 1 'esprit du sujet.

The University of Kansas 


\section{Notes}

1

Alexis François, Le Premier Baiser de

$L^{\prime}$ amour ou Jean-Jacques Rousseau inspirateur d'Estampes (Genève, Editions Sonor, 1920). Ce petit livre qui avait une première édition de seulement trois cent exemplaires en 1920, vient d'être ré-édité par slatkin Reprints.

2

Dans une lettre à son éditeur, Marc-Michel Rey, du 21 juin 1759. Citée par Alexis François, p. 13 .

3

Cité par François, p. 8. Ces paroles se trouvent dans une lettre d'Henri Meister en 1764.

4

Dans une lettre à Madame d'Houdetot du 26 décembre 1756. Citée par François, p. 11.

5

Dans une lettre à Coindet, le 13 février 1761. Citée par François, p. 18.

6

Dans une lettre à Coindet, sans date. Citée par François, p. 16. 